\title{
Correction: Using water temperature series and hydraulic heads to quantify hyporheic exchange in the riparian zone
}

Jie Ren ${ }^{1} \cdot$ Wenbing Zhang ${ }^{1} \cdot$ Jie Yang ${ }^{1} \cdot$ Yinjun Zhou ${ }^{2}$

Published online: 6 June 2020

(C) Springer-Verlag GmbH Germany, part of Springer Nature 2020

Correction: Hydrogeology Journal (2019) 27:1419-1437 https://doi.org/10.1007/s10040-019-01934-z

The original version of this article unfortunately contained an incorrect citation. The citation of Munz et al. (2017) on page 1421 (section 'Model tools') was a mistake, as Munz et al. (2017) did not use COMSOL to simulate water flow and heat transport.

Model tools presented in this article are not affected by this incorrect citation.

The online version of the original article can be found at https://doi.org/ 10.1007/s10040-019-01934-Z

Jie Ren

renjie@xaut.edu.cn

1 State Key Laboratory of Eco-hydraulics in Northwest Arid Region of China, Xi'an University of Technology, Xi'an 710048, China

2 Changjiang River Scientific Research Institute, Wuhan 430010, China 